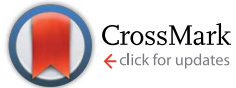

Cite this: RSC Adv., 2017, 7, 5451

Received 8th October 2016 Accepted 29th December 2016

DOI: $10.1039 / c 6 r a 24891 h$

www.rsc.org/advances

\section{Unique microstructure of an oil resistant nitrile butadiene rubber/polypropylene dynamically vulcanized thermoplastic elastomer}

\author{
Nanying Ning, ${ }^{a}$ Xiangyan Li, ${ }^{a}$ Hongchi Tian, ${ }^{a}$ Yueqing Hua, ${ }^{a}$ Hongli Zuo, ${ }^{a}$ \\ Pengjun Yao, ${ }^{\star a b}$ Liqun Zhang, ${ }^{\text {ab }}$ Youping $\mathrm{Wu}^{\text {ab }}{ }^{\mathrm{ab}}$ Gu-Hua $\mathrm{Hu}^{\mathrm{c}}$ and Ming Tian*ab
}

\begin{abstract}
This paper reports on the microstructure, morphological evolution and the properties of oil resistant nitrile butadiene rubber (NBR)/polypropylene (PP) thermoplastic vulcanizates (TPVs) prepared by dynamical vulcanization (DV). The as prepared NBR/PP TPVs exhibited good mechanical properties, good elasticity, easy processability and good oil resistance. Interestingly, the dispersed NBR microparticles in the NBR/PP TPVs were actually the agglomerates of secondary NBR microparticles with a diameter of about $1.7 \mu \mathrm{m}$ and the phase inversion of the NBR/PP TPVs during DV was dominated by the formation and agglomeration of these secondary NBR microparticles. More interestingly, many PP domains were embedded in the dispersed crosslinked NBR phase, attributed to the chemical reaction between the compatibilizers amine-terminated butadiene-acrylonitrile copolymer (ATBN) and maleic anhydride grafted polypropylene (MP) and the voids among the spherical secondary NBR microparticles. As the DV proceeded, the size of the dispersed NBR agglomerates and the thickness of the PP ligaments in the NBR/PP TPVs decreased, leading to the increase in the density of the NBR agglomerates and the strengthening in the rubber network of the NBR/PP TPVs. As a result, the mechanical properties, the elasticity and the oil resistance of the NBR/PP TPVs were obviously improved as the DV proceeded.
\end{abstract}

\section{Introduction}

Thermoplastic vulcanizates (TPVs) are a special class of thermoplastic elastomers (TPEs) prepared by a special polymer reactive blending technique, dynamic vulcanization (DV). ${ }^{1}$ After DV, a high-content of selectively crosslinked rubber phase of micro- or nano-size is dispersed in a low-content of continuous thermoplastic phase in TPVs. ${ }^{2-4}$ Thus, TPVs combine the good elasticity of traditional thermoset rubbers and the good melt processability and recyclability of thermoplastics, and have been widely used in automobile, construction, and electronics. ${ }^{5}$ Nowadays, due to the requirements of resource saving, environmental protection and sustainable development, TPVs are considered as typical "green" polymers to replace the unrecyclable petroleum-based thermoset rubbers and have attracted more and more attention in both academia and industry. ${ }^{6,7}$

${ }^{a}$ Key Laboratory of Beijing City on Preparation and Processing of Novel Polymer Materials, Beijing University of Chemical Technology, Beijing 100029, China. E-mail: tianm@mail.buct.edu.cn; yaopj171512@126.com; Fax: +8610 64433964; Tel: +861064434860

${ }^{b}$ Key Laboratory of Carbon Fiber and Functional Polymers, Beijing University of Chemical Technology, Beijing 100029, China

'Laboratory of Reactions and Process Engineering, University of Lorraine-CNRS, Nancy, France
Usually, the most important properties of TPVs including the mechanical property, the elasticity and the rheological property all depend on the microstructure of TPVs. Specifically, the content and crosslinking degree of the rubber phase and the blend ratio, ${ }^{8}$ the size and size distribution of the rubber phase ${ }^{9}$ and the corresponding rubber network structure, ${ }^{10}$ the thickness of the plastic ligaments ${ }^{11}$ and the compatibility between the plastic and the rubber phases ${ }^{12,13}$ play key roles in these properties of TPVs. A high-content (60 to $80 \mathrm{wt} \%$ ) of rubber phase is required to obtain good elasticity of TPVs, resulting in a continuous rubber phase in plastic/rubber premix before DV. However, a continuous plastic phase is required to obtain easy processability. Thus, the phase inversion of the rubber phase from continuous phase (in premix) to dispersed phase (in TPVs) is a key to prepare TPVs. ${ }^{\mathbf{1 4}, 15}$ Thus, it is significant to study the microstructure, the formation mechanism and the microstructure-property relationship in order to provide guidance for the morphological control and preparing high-performance TPVs. ${ }^{16-18}$ Because the ethylene-propylene-diene terpolymer (EPDM)/polypropylene (PP) TPVs is the most widely-used industrialized TPVs products nowadays, most previous studies in the literature were focused on the phase morphology and properties of EPDM/PP TPVs during DV. ${ }^{19-23}$

Nitrile butadiene rubber (NBR) is well known for its good oil resistance. NBR/polypropylene (PP) TPVs show good mechanical properties, good cold resistance and ozone resistance which 
are bad in crosslinked NBR. ${ }^{12}$ What's more, NBR/PP TPVs show good oil resistance and heat resistance. Up to know, some studies have been focused on the preparation, crosslinking, compatibilization and mechanical properties of NBR/PP TPVs. ${ }^{24-27}$ However, few studies were focused on the microstructure, the formation mechanism and the microstructureproperty relationship of NBR/PP TPVs.

In our previous studies, it was found that the dispersed rubber microparticles in miscible rubber/plastic systems such as EPDM/PP TPVs and bromo-isobutylene-isoprene rubber (BIIR)/PP TPVs were actually agglomerates of rubber nanoparticles (40 to $100 \mathrm{~nm}$ ). ${ }^{28,29}$ In this study, we aim to find out what is the microstructure and formation mechanism in the immiscible oil resistant NBR/PP TPVs. We deeply studied the microstructure and its formation mechanism, and the microstructure-properties (including mechanical property, elasticity, rheological property and oil resistance) relationship of NBR/PP TPVs during DV to provide guidance for the preparation of high-performance NBR/PP TPVs. We also deeply studied the variation of the crosslinking degree of the rubber phase, the variation of the size of rubber phase and the rubber network, and the phase inversion during DV. To improve the compatibility between NBR and PP maleic anhydride grafted polypropylene (MP) and amine-terminated butadieneacrylonitrile copolymer (ATBN) were used as compatibilizer.

\section{Experimental}

\subsection{Materials}

PP (4220), with melt flow index $\left(230{ }^{\circ} \mathrm{C}, 2.16 \mathrm{~kg}\right)$ of $0.24 \mathrm{~g} /$ 10 min, was supplied by Yanshan Petrochemical (China). NBR (230 s), with acrylonitrile content of $35 \%$, was supplied by Nippon (Japan). The compatibilizer maleic anhydride grafted polypropylene (MP) (353 D) was supplied by Dupont (United State) and the compatibilizer amine-terminated butadieneacrylonitrile copolymer $($ ATBN) $($ HYCAR-ATBN $1300 \times 16)$ was provided by Noveon (China). $\mathrm{SnCl}_{2} \cdot \mathrm{H}_{2} \mathrm{O}$, dimethylol phenolic resin (SP 1045) and pentaerythritol tetrakis 3-(3,5-di-tert-butyl-4hydroxyphenyl)-propionate (antioxidant 1010) were all commercially available.

\subsection{Sample preparation}

NBR/PP TPVs was prepared by DV in a Haake Rheomix (600 OS internal mixer, Thermo Fisher Scientific, United State) equipped with two counter-rotating rotors. The mass ratio of NBR/ ATBN/MP/PP is 60/10/20/10. ${ }^{26}$ NBR and ATBN were first mixed at room temperature and then mixed with MP and PP in the Haake Rheomix at $180{ }^{\circ} \mathrm{C}$. The curing agents were added into the cooled-down NBR/PP premix at room temperature, resulting in morphology of PP dispersed in NBR matrix. The obtained NBR/PP blend was dynamically vulcanized in the Haake Rheomix at $180{ }^{\circ} \mathrm{C}$ with a rotor speed of $80 \mathrm{rpm}$. Five samples (designated as A, B, C, D and E) with different extents of vulcanization were selected during DV. The compositions of the NBR/PP TPVs were optimized according to our previous study, and are shown in Table 1.
Table 1 Compositions of NBR/PP TPVs

\begin{tabular}{ll}
\hline Ingredients & Content of the ingredients \\
\hline NBR & 60 \\
ATBN & 10 \\
PP & 20 \\
MP & 10 \\
1010 & 0.5 \\
$\mathrm{SnCl}_{2} \cdot \mathrm{H}_{2} \mathrm{O}$ & 1.1 \\
$\mathrm{SP} 1045$ & 5.6
\end{tabular}

\subsection{Characterization}

2.3.1. Volume swell ratio measurements. The reciprocal volume swell ratios $(1 / Q)$ of samples A to $\mathrm{E}$ were measured to characterize the crosslinking degree of the NBR phase in the samples A to $\mathrm{E}^{\mathbf{3 0}}$ as has been described in our previous studies. ${ }^{29,31}$

2.3.2. Morphology studies. The morphologies of samples A to E were observed using a Nanoscope IIIa peak force tapping atom force microscope (PF-AFM) (Bruker, Germany), samples were microtomed and polished using a cryo-ultramicrotome (Leica EM UC7, Germany) equipped with a glass knife at $-100{ }^{\circ} \mathrm{C}$ before observed, and the particle size was determined with Image-Pro Plus 4.5 software based on the AFM graphs, as has been described in our previous studies. ${ }^{29,31}$ For each sample, more than 50 particles in at least five different AFM pictures were examined to obtain statistically meaningful results.

2.3.3. Disintegration tests. Disintegration tests were carried out as reported in our previous studies ${ }^{29,31}$ by immersing samples in hot 1,2,4-trichlorobenzene (TCB) at $180^{\circ} \mathrm{C}$ for $50 \mathrm{~h}$ or less, and photographs of the final states of the samples after immersion were taken. All samples were first heated in vacuum oven at $180{ }^{\circ} \mathrm{C}$ for $5 \mathrm{~min}$ in order to make sure that the NBR phase was totally crosslinked. The morphologies of totally disintegrated samples $\mathrm{C}$ to $\mathrm{E}$ and partially disintegrated sample $\mathrm{E}$ were observed by a Hitachi (Japan) S-4800 scanning electron microscopy (SEM) after coated with a thin layer of gold. The size of the NBR particles in totally disintegrated samples $\mathrm{C}$ to $\mathrm{E}$ were determined based on the SEM images with Image-Pro Plus 4.5 software. At least 50 particles were examined to obtain statistically meaningful results.

2.3.4. Rubber network and rheological behavior measurements. The rubber networks ${ }^{18}$ and the rheological properties of the samples $\mathrm{C}$ to $\mathrm{E}$ were measured by a rubber process analyzer (RPA 150 2000, Alpha Technologies, USA), as have been described in our previous studies..$^{29,31}$

2.3.5. Tensile and tensile recovery tests. The tensile testing of TPVs (samples C to E) were measured according to ASTM D412 and the elasticity of the TPVs (samples C to E) were studied by strain recovery test at $200 \mathrm{~mm} \min ^{-1} \cdot{ }^{29}$ Samples were first deformed up to a total strain of $50 \%$ and then the tensile force was relaxed to zero during tensile recovery tests, the residual strain is defined as the permanent set. The hysteresis loss at $50 \%$ deformation was calculated by subtracting the area under the force-retraction curve from the area under the force- 
deformation curve. ${ }^{32}$ The detailed test conditions have been described in our previous studies. ${ }^{29,31}$

2.3.6. Oil resistance measurements. Oil resistance of samples C to E, statically vulcanized NBR and neat PP were measured according to ASTM D 471. It should be noted that the dosage of crosslinking agents in NBR vulcanizate is the same with that in the NBR phase in NBR/PP TPVs. The samples were first immersed in $32^{\#}$ engine oil at $120{ }^{\circ} \mathrm{C}$ for $24 \mathrm{~h}$, and then removed from the oil and wiped with filter paper to remove the excess oil from the surface. The changes of samples in weight $(\Delta W)$ and volume $(\Delta V)$ were calculated by measuring the weights of samples in air and alcohol before and after immersion.

\section{Results and discussion}

\subsection{Variation of crosslinking degree in NBR phase during DV}

The crosslinking degree of the rubber phase has a significant effect on the phase morphology of TPVs. According to the torque-time curve and the temperature-time curve (see Fig. 1), five samples A to E were selected to study the variation of crosslinking degree during DV. The reciprocal volume swell ratios (1/ $Q)$ of the samples were measured to represent the crosslinking degree of the NBR phase during $D V .{ }^{30}$ A higher $1 / Q$ value represents a higher crosslinking degree. At the initial stage of $\mathrm{DV}$, the NBR/PP blend melted quickly and the torque declines dramatically to a minimum at $\mathrm{A}$, where the crosslinking degree of the NBR phase is low. With the increase in DV time, the rapid crosslinking of the NBR phase leads to the rapid increase in the viscosity of the NBR phase and thus the large increase in the torque until a peak occurs at B. With the further increase in DV time, the crosslinking degree of the NBR phase continues to increase from $\mathrm{B}$ to $\mathrm{C}$ where the torque declines sharply, indicating the occurrence of phase inversion. ${ }^{19}$ As the DV further proceeds, the crosslinking degree of the NBR phase and the torque of the NBR/PP blend levels off from $\mathrm{C}$ to $\mathrm{E}$, where sample $\mathrm{D}$ was selected at $5 \mathrm{~min}$ and sample $\mathrm{E}$ was selected at $10 \mathrm{~min}$. Thus, the crosslinking of the NBR phase mainly occurs at the early stage of the DV process, consistent well with that reported in previous studies. ${ }^{\mathbf{1 8 2 8}}$

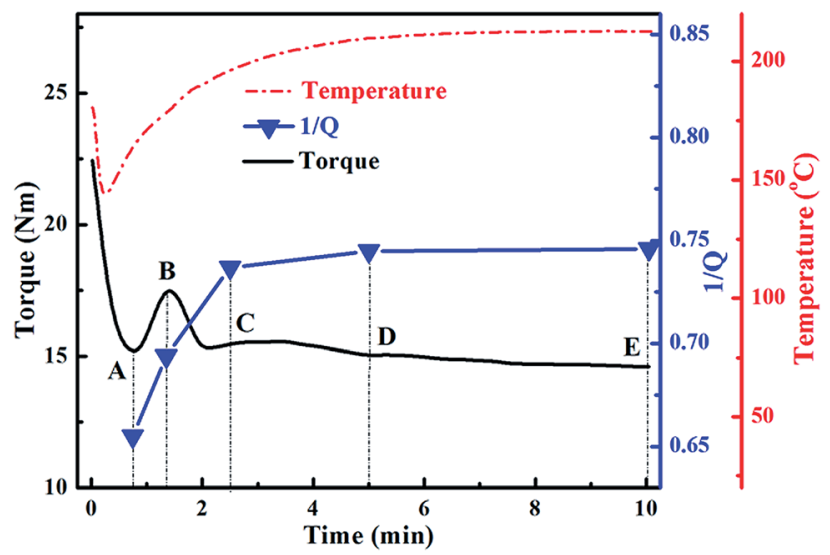

Fig. 1 Variations of torque, temperature and reciprocal swell ratio $1 / Q$ with mixing time during DV for NBR/PP TPVs.

\subsection{Phase morphology and morphological evolution during DV}

To study the morphological evolution of the NBR/PP TPVs during DV, the phase morphologies of sample A to $\mathrm{E}$ were observed by using AFM and the results are shown in Fig. 2. The darker regions represent the PP phase and the lighter regions represent the NBR phase. At the initial state, the PP phase is dispersed in the continuous NBR phase due to the high content and low crosslinking degree of the NBR phase, as shown in Fig. 2(a). The breakup and coalescence of the NBR phase occurs simultaneously under shear. ${ }^{28}$ As the DV proceeds, the crosslinking degree of the NBR phase increases from A to B (see Fig. 1) and the PP phase in sample $B$ is still dispersed in the continuous NBR phase (see Fig. 2(b)), implying that the NBR phase can coalesce and the phase inversion has not occurred. As the crosslinking degree of the NBR phase further increases to $\mathrm{C}$ (see Fig. 1), the viscosity of the NBR phase largely increase ${ }^{\mathbf{1 5}}$ and the NBR phase can not coalesce but transform into dispersed phase in the continuous PP matrix in sample C (see Fig. 2(c)), indicating the completion of the phase inversion. Here, the diameter of the dispersed NBR phase in sample $\mathrm{C}$ is bigger than $30 \mu \mathrm{m}$, and the shape of the dispersed NBR is irregular. With the further increase in DV time from $\mathrm{C}$ to $\mathrm{E}$, the shape of the dispersed NBR in sample $\mathrm{E}$ is still irregular and the diameter of the dispersed NBR phase decreases to about 3-8 $\mu \mathrm{m}$ (see Fig. 2(c)-(e)), leading to the increase in the density of the dispersed NBR phase and the decrease in the thickness of the PP ligaments. ${ }^{18,33}$ Interestingly, it can be seen in Fig. 2(c)-(e) that many PP domains are embedded in the dispersed crosslinked NBR phase in samples $\mathrm{C}$ to $\mathrm{E}$, ascribed to the chemical reaction between the compatibilizers ATBN and MP. ${ }^{12,26}$

To further conform the phase morphologies and the phase inversion of the NBR/PP samples during DV, disintegrating tests were carried out and the photographs of samples $\mathrm{A}$ to $\mathrm{E}$ immersed in 1,2,4-trichlorobenzene (TCB) at $180^{\circ} \mathrm{C}$ for $50 \mathrm{~h}$ or less are shown in Fig. 3. It should be noted here that PP can be dissolved in TCB at $180{ }^{\circ} \mathrm{C}$ within $10 \mathrm{~h}$ while crosslinked NBR does not dissolve in TCB. At the initial state, the PP phase is dispersed in the continuous NBR phase due to the low content of PP. Sample A and B do not disintegrate even after $50 \mathrm{~h}$ (see Fig. 3(a)), indicating that the NBR phase in samples A and B is the continuous phase or co-continuous phase and the phase inversion has not occurred. Fig. 3(b) shows that samples $\mathrm{C}$ to $\mathrm{E}$ are completely disintegrated after immersion in TCB for $20 \mathrm{~h}$ (sample $\mathrm{C}$ ) to $27 \mathrm{~h}$ (sample $\mathrm{E}$ ), respectively, indicating that the NBR phase is dispersed in the continuous PP phase and the phase inversion has completed in sample $\mathrm{C}$. The increase in disintegration time of samples $\mathrm{C}$ to $\mathrm{E}$ implies that the rubber network in the samples is strengthened as the DV proceeds from $\mathrm{C}$ to $\mathrm{E}$.

To investigate the dispersed NBR particles in samples $\mathrm{C}$ to $\mathrm{E}$, the morphologies of the totally disintegrated samples were observed by using SEM and the micrographs are shown in Fig. 4. It can be seen that the dispersed NBR particles in samples $\mathrm{C}$ to $\mathrm{E}$ are all single spherical microparticles with a diameter of about $1.7 \mu \mathrm{m}$ and the size of the microparticles is 

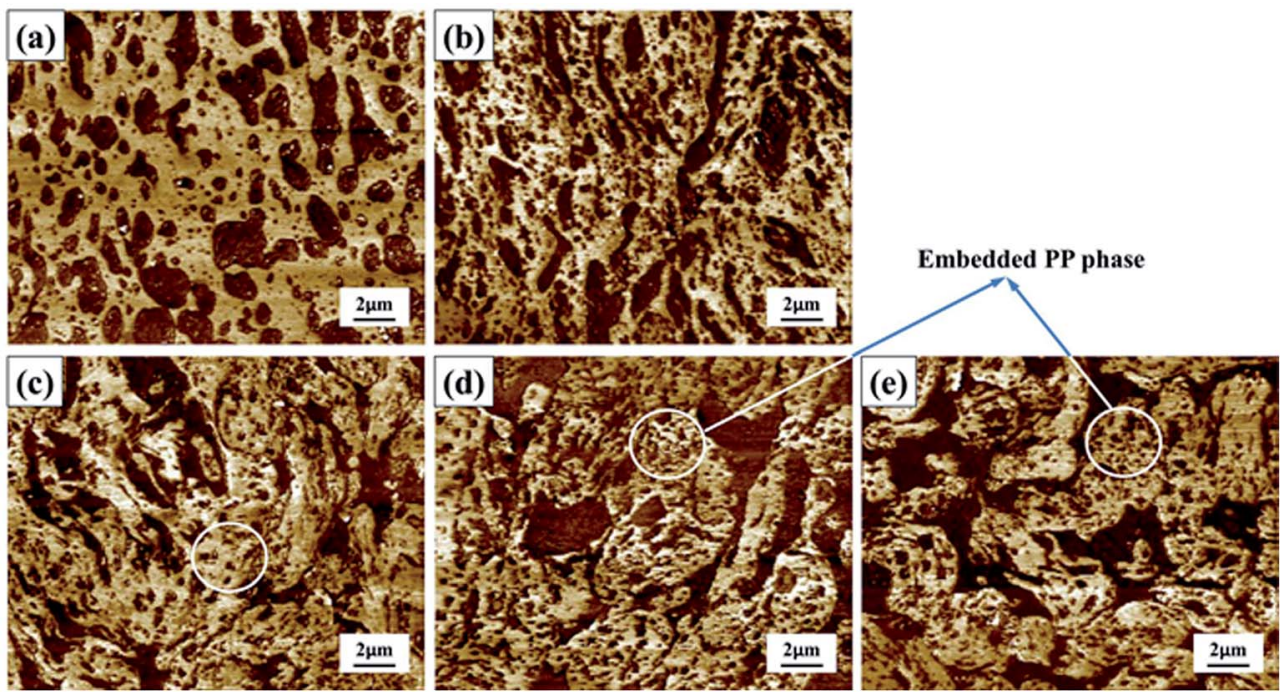

Fig. 2 AFM micrographs of NBR/PP samples (the darker regions represent the PP phase and the lighter regions represent the NBR phase): (a) sample A; (b) sample B; (c) sample C; (d) sample D; (e) sample E.

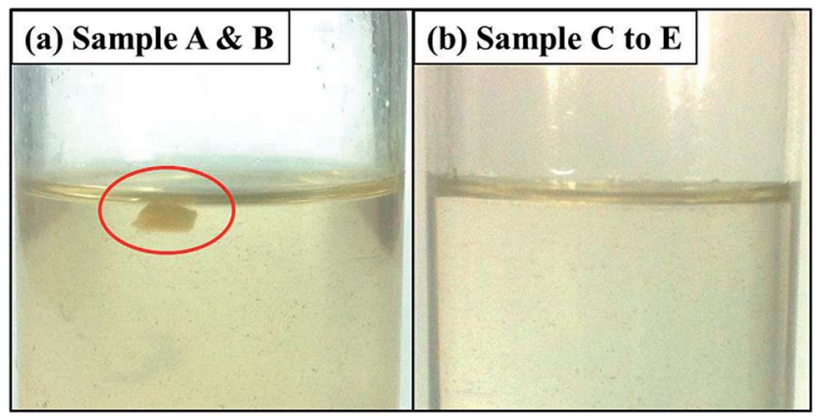

Fig. 3 Final states of samples after immersed in 1,2,4-trichlorobenzene at $180^{\circ} \mathrm{C}$ for $50 \mathrm{~h}$ or less: (a) sample A and sample B, both not disintegrated; (b) samples $C$ to $E$, respectively, all totally disintegrated

almost identical. The surfaces of these NBR microparticles are rough, ascribed to the chemical reaction between the compatibilizers ATBN and MP, as previously reported. ${ }^{12,26}$ Interestingly, the sizes of the NBR microparticles in the SEM micrographs of these samples are much smaller than that in AFM micrographs (Fig. 2) and the shape is more regular.

To further confirm the size of the dispersed NBR phase, sample $\mathrm{E}$ was partially disintegrated after immersed in TCB at
$180{ }^{\circ} \mathrm{C}$ for $15 \mathrm{~h}$. The photograph and SEM micrographs of partially disintegrated sample $\mathrm{E}$ were taken and the results are shown in Fig. 5. It can be seen that the dispersed NBR phase in the NBR/PP TPVs is actually the agglomerate of smaller NBR microparticles (called secondary NBR microparticles) with a diameter of about $1.7 \mu \mathrm{m}$, and the shape and size of these secondary NBR microparticles observed in the NBR agglomerate are similar with that in Fig. 4 . The results are similar with that reported in our previous studies on EPDM/PP TPVs, in which EPDM microparticles are formed by agglomerates of EPDM nanoparticles. ${ }^{18,28}$ The difference is that the diameters of the EPDM particles range from $40-60 \mathrm{~nm}$ while the diameters of the secondary NBR microparticles are about $1.7 \mu \mathrm{m}$. In addition, the voids among the spherical secondary NBR microparticles results in the formation of embedded PP domains in NBR agglomerates.

As previously reported, the rubber particles with high crosslinking degree and elastic modulus can be regarded as fillers. ${ }^{28}$ The phase inversion in the NBR/PP samples during DV indicates that samples $\mathrm{C}$ to $\mathrm{E}$ are TPVs where the NBR particles with high crosslinking degree are dispersed in the PP matrix. Thus, the rubber networks of samples $\mathrm{C}$ to $\mathrm{E}$ were characterized by the change in storage modulus with the increase in shear strain using rubber process analyzer (RPA), and the results are
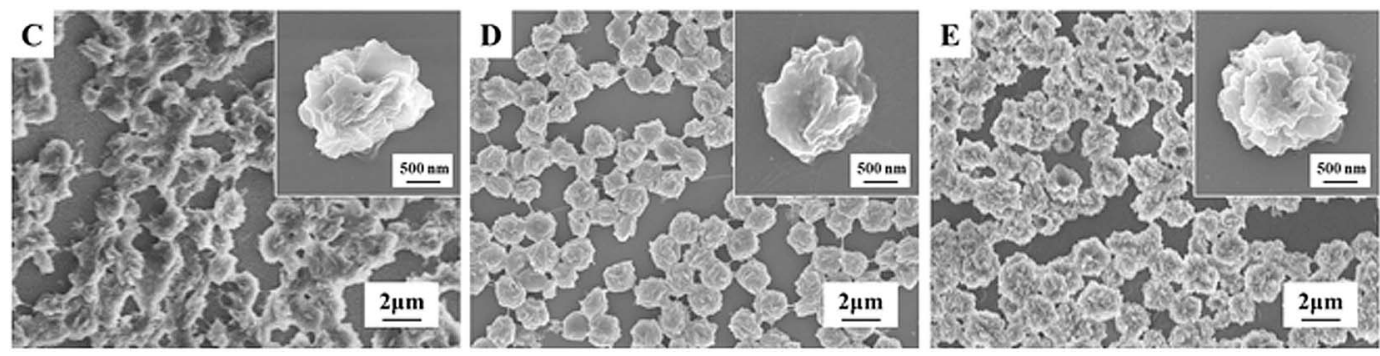

Fig. 4 SEM micrographs of totally disintegrated samples $C$ to $E$. 


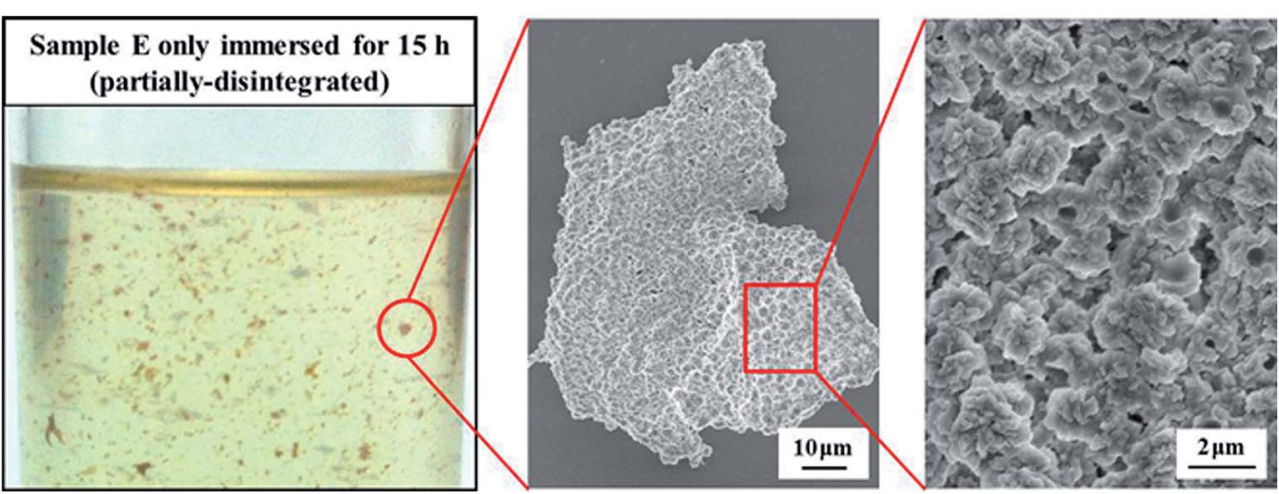

Fig. 5 Photograph and SEM micrographs of sample E only immersed for $15 \mathrm{~h}$ (partially disintegrated).

shown in Fig. 6. For comparison, neat PP was also characterized by using RPA. The change between the maximum and the minimum of the storage modulus $G^{\prime}\left(\Delta G^{\prime}\right)$ represents the rubber network and the higher $\Delta G^{\prime}$ implies the stronger rubber network. ${ }^{34,35}$ The $\Delta G^{\prime}$ at the same shear strain increases as the DV proceeds from $\mathrm{C}$ to $\mathrm{E}$, indicating the strengthening of the rubber network. The strengthening of the rubber network is consistent well with the AFM results and the disintegrating results, demonstrating the increase in the density of the dispersed NBR phase and the decrease in the thickness of PP ligaments. The rubber network has significant effect on the mechanical property, elasticity, and rheological property of the NBR/PP TPVs, which will be discussed later.

\subsection{Mechanism for the formation of phase morphology}

A schematic illustration of the morphological evolution in NBR/ PP TPVs during DV was proposed in Fig. 7 to show the formation of the secondary NBR microparticles and the variation of the NBR agglomerates, which play an important role in the properties of TPVs. The yellow regions represent the NBR phase and the blue regions represent the PP phase. At the initial state, the PP phase is dispersed in the NBR phase due to the high

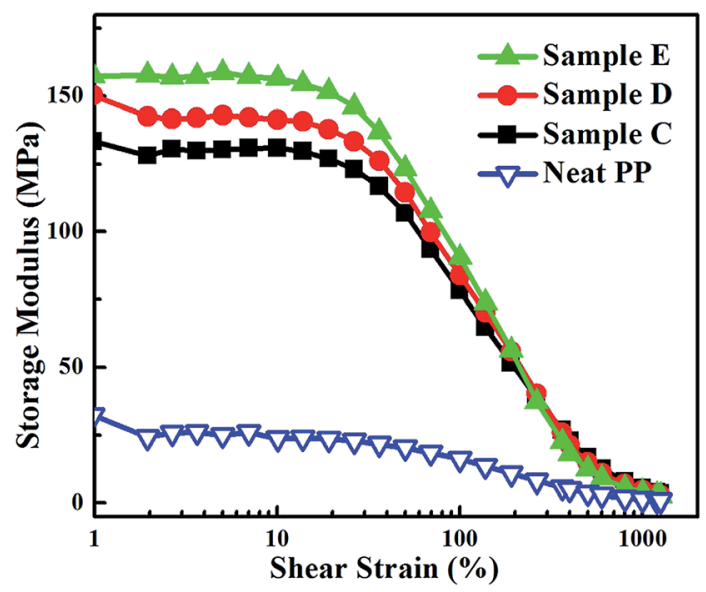

Fig. 6 Storage modulus $\left(G^{\prime}\right)$ versus strain with a frequency of $0.2 \mathrm{~Hz}$ of samples $C$ to $E$ and neat PP. content of the NBR phase, as is shown in Fig. 7(i). Many NBR domains are embedded in the dispersed PP phase, ascribed to the chemical reaction between the compatibilizers ATBN and MP, as previously reported. ${ }^{12,26}$ As the DV begins, the NBR phase can be broken up into a large number of NBR microdroplets under shear, as demonstrated in our previous study. ${ }^{18,28,29}$ Because of the inhomogeneity of the crosslinking degree, some of the NBR microdroplets with low crosslinking degrees can still coalesce while others are in situ vulcanized and transform into NBR microparticle agglomerates, as is shown in Fig. 7(ii). With the increase in the crosslinking degree, all the NBR microdroplets cannot coalesce but dispersed in the PP phase as NBR microparticles agglomerates, and the phase inverses, as is shown in Fig. 7(iii). Thus, the phase inversion in the NBR/PP TPVs depends on the formation and agglomeration of secondary NBR microparticles formed by the breakup and in situ vulcanization of NBR microdroplets at the early stage of the DV. And the voids among the spherical secondary NBR microparticles results in the formation of embedded PP domains in NBR agglomerates. With the further increase in DV time, the size of the NBR agglomerates decreases, resulting in the increase in the number of NBR agglomerates and the decrease in the thickness of the PP ligaments, as is shown in Fig. 7(iv). The mechanism of the morphological evolution of NBR/PP TPVs during DV is obviously different from that of EPDM/PP TPVs and BIIR/PP TPVs, and BIIR/Nylon-12 TPVs etc. ${ }^{18,28,29,31}$

\subsection{Properties of NBR/PP TPVs}

The phase morphology and morphological evolution, especially the size of the dispersed rubber phase, have significant effects on the properties of TPVs. ${ }^{11}$ Thus, the properties including the mechanical property, the elasticity, the rheological property and the oil resistant, and the microstructure-property relationships of the samples $\mathrm{C}$ to $\mathrm{E}$ were studied in order to provide guidance for the preparation of high-performance NBR/PP TPVs for its application in oil-resistant products.

3.4.1. Mechanical property. Fig. 8 shows the stress-strain curves of samples $\mathrm{C}$ to $\mathrm{E}$ and the variations of the tensile stress and the elongation at break. It can be seen that the tensile stress increases from 9.5 MPa to $15.5 \mathrm{MPa}$ and the elongation at break increases from $444 \%$ to $635 \%$ as the DV proceeds from sample 

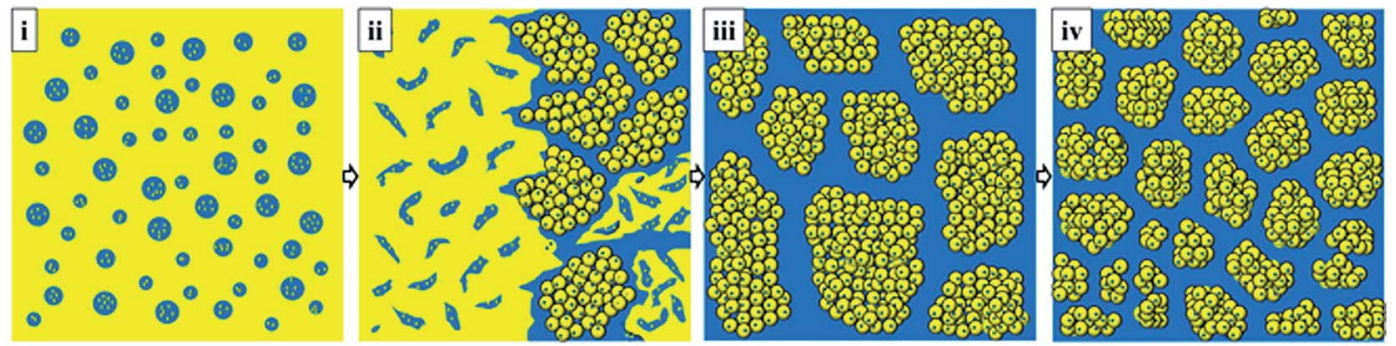

Fig. 7 Schematic illustration of morphological evolution of NBR/PP TPVs during DV (the yellow regions represent PP phase and the blue regions represent the NBR phase).
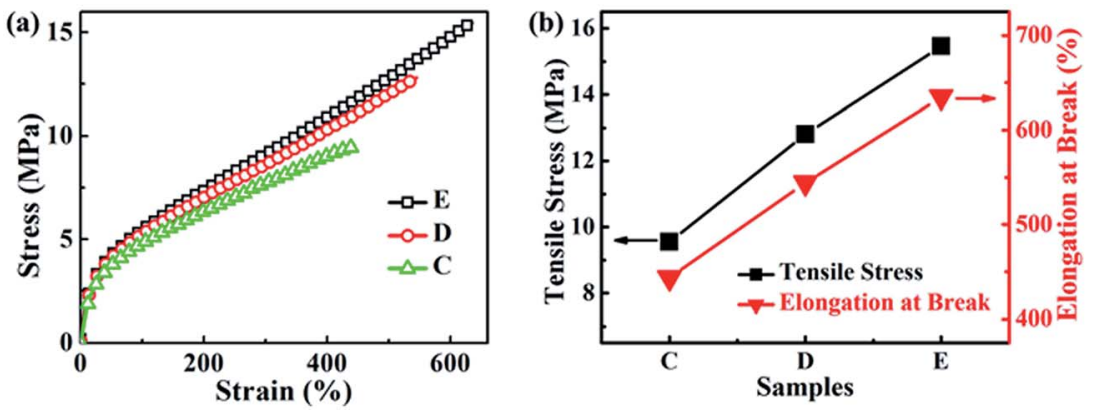

Fig. 8 (a) Stress-strain curves and (b) variations of tensile stress and elongation at break of samples $C$ to $E$.

C to sample E, indicating the improvement of mechanical property. The increase in the tensile stress and the elongation at break is ascribed to the decrease in $d_{\mathrm{n}}$ (the increase in the interfacial surface area of rubber phase) and the strengthening in the rubber network, similar with that reported in previous studies. ${ }^{\mathbf{1 1 , 1 8 , 2 8 , 2 9}}$ Compared with traditional thermoset NBR products as previously reported, ${ }^{36}$ our NBR/PP TPVs shows higher tensile stress due to the continuous PP matrix.

3.4.2. Elasticity. Elasticity caused by the high content and high crosslinking degree of the NBR phase in TPVs, has significant effect on the hardness and the dynamic fatigueresistance property of TPVs products. The tensile recovery tests of samples $\mathrm{C}$ to $\mathrm{E}$ were carried out to study the elasticity of the samples. The permanent set and the hysteresis loss summarized according to the tensile recovery curves are two important parameters to represent the elasticity of TPVs. Low permanent set and hysteresis loss represents high elasticity. ${ }^{32,37}$ It can be seen from Fig. 9 that both the permanent set and the hysteresis loss decrease as the DV proceeds from $\mathrm{C}$ to $\mathrm{E}$, indicating the increase in the elasticity. The decrease in the thickness of the PP ligaments and the strengthening of the rubber network lead to the decrease in the stress required for bending or buckling, ${ }^{38}$ and thus improving the elasticity of the NBR/PP TPVs. In addition, according to ASTM D1566-07a, our NBR/PP TPVs is an elastomer with high elasticity because the permanent set of the NBR/PP TPVs samples range from $12.9 \%$ to $13.4 \%$. The good elasticity of TPVs can result in low hardness and high dynamic fatigue-resistance of the TPVs products. In addition, the elasticity of the NBR/PP TPVs can be further improved by controlling the formula during production.

3.4.3. Rheological property. Rheological property, dominated by the continuous plastic matrix, plays an important role
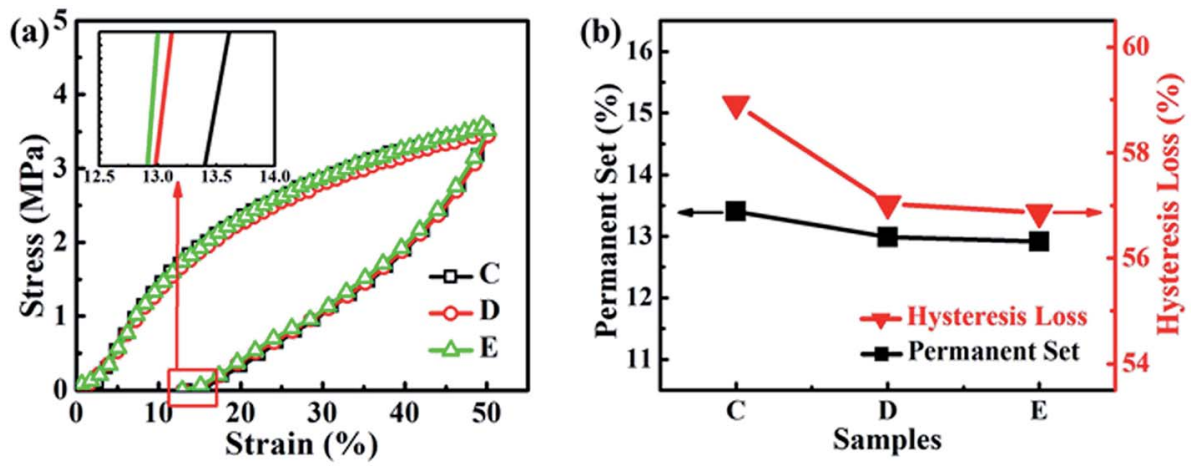

Fig. 9 (a) Tensile recovery curves and (b) variations of permanent set and hysteresis loss of samples $C$ to $E$. 
in the melt processability, the recyclability and the production efficiency of TPVs. Good rheological property represents easy melt processability, easy recyclability and high production efficiency. The rheological properties of samples $\mathrm{C}$ to $\mathrm{E}$ were studied by using RPA and the results are shown in Fig. 10. Low storage modulus $\left(G^{\prime}\right)$ and complex viscosity $\left(\eta^{*}\right)$ represents good rheological property of TPVs. It can be seen from Fig. 10 that both the storage modulus $\left(G^{\prime}\right)$ and the complex viscosity $\left(\eta^{*}\right)$ increase slightly at a given frequency, indicating that the rheological property of the NBR/PP TPVs deteriorates slightly as the DV proceeds from $\mathrm{C}$ to $\mathrm{E}$. The slight deterioration of the rheological property is ascribed to the decrease in the thickness of the PP ligaments and the strengthening in the rubber network caused by the decrease in the size of the dispersed NBR phase. Importantly, all these TPVs samples $\mathrm{C}$ to $\mathrm{E}$ show easy processability, facilitating the industrial production of the NBR/PP TPVs. In addition, compared with traditional thermoset NBR products, our NBR/PP TPVs can save raw materials by recycling the leftover materials during production and then save the cost because of the good melt processability of TPVs.

3.4.4. Oil resistance. The oil resistant of samples $\mathrm{C}$ to $\mathrm{E}$, statically vulcanized NBR and neat PP were measured by immersed in $32^{\#}$ engine oil at $120{ }^{\circ} \mathrm{C}$ for $24 \mathrm{~h}$. The changes in weight $(\Delta W)$ and volume $(\Delta V)$ of samples were calculated before and after immersion, and low $\Delta W$ and $\Delta V$ represent high oil resistant. It can be seen in Table 2 that both PP and NBR show good oil resistance, and NBR shows much better oil resistance. The NBR/PP TPVs also show good oil resistance between that of NBR and PP. As the DV proceeded from $\mathrm{C}$ to $\mathrm{E}$, the size of the

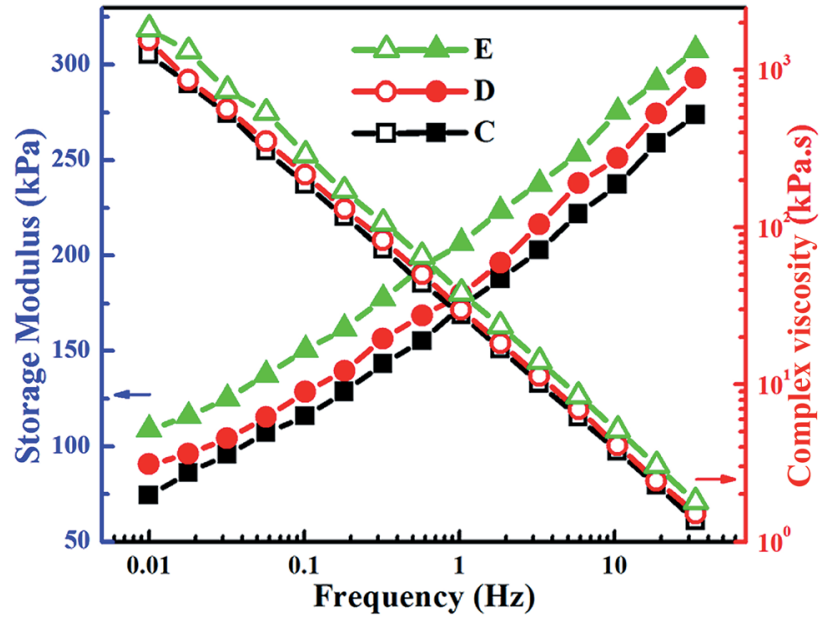

Fig. 10 Storage modulus $\left(G^{\prime}\right)$ and complex viscosity $\left(\eta^{*}\right)$ versus angular frequency $(\omega)$ at $180^{\circ} \mathrm{C}$ of samples $\mathrm{C}$ to $\mathrm{E}$.

Table 2 Changes in weight $(\Delta W)$ and volume $(\Delta V)$ of sample $C$ to $E, P P$ and NBR before and after immersed in engine oil at $120^{\circ} \mathrm{C}$ for $24 \mathrm{~h}$

\begin{tabular}{llllll}
\hline Changes & PP & NBR & C & D & E \\
\hline$\Delta W, \%$ & +10.6 & +2.2 & +5.6 & +4.9 & +4.5 \\
$\Delta V, \%$ & +10.4 & +2.5 & +5.3 & +4.8 & +4.5
\end{tabular}

NBR agglomerate decreased leading to the increase in the density of the dispersed NBR phase and the strengthening in the rubber network. Thus, the number of the crystal nucleus (dispersed NBR phase) increases as we previously studied, ${ }^{12}$ facilitating the crystallization of the NBR/PP TPVs and the oil resistance.

\section{Conclusions}

We successfully prepared NBR/PP TPVs by DV and studied the microstructure, the morphological evolution during DV and the properties of the NBR/PP TPVs. The corresponding mechanism for the formation and evolution of the microstructure was proposed based on the crosslinking degree of the rubber phase. The results indicate that the dispersed NBR microparticles in the NBR/PP TPVs are actually the agglomerates of secondary NBR microparticles with a diameter of about $1.7 \mu \mathrm{m}$ formed by the breakup and in situ vulcanization of NBR microdroplets at the early stage of the DV. The phase inversion of the NBR/PP TPVs during DV is dominated by the formation and agglomeration of these secondary NBR microparticles, similar with those observed in EPDM/PP TPVs and BIIR/PP TPVs. Interestingly, many PP domains are embedded in the dispersed crosslinked NBR phase, ascribed to the chemical reaction between the compatibilizers ATBN and MP and the voids among the spherical secondary NBR microparticles. As the DV proceeds, the size of the dispersed NBR agglomerates and the thickness of the PP ligaments in NBR/PP TPVs decrease, leading to the increase in the density of the NBR agglomerates, the strengthening in the rubber network and the increase in the crystallinity of the NBR/PP TPVs. As a result, the rheological property is slightly deteriorated, and the mechanical property, the elasticity and the oil resistance are obviously improved as the DV proceeds.

\section{Acknowledgements}

We gratefully acknowledge the National Natural Science Foundation of China (Grant No. 51525301, 51673014, 51521062) for financial supports.

\section{References}

1 S. S. Banerjee and A. K. Bhowmick, Polymer, 2015, 57, 105116.

2 A. Thitithammawong, C. Nakason, K. Sahakaro and J. W. M. Noordermeer, Eur. Polym. J., 2007, 43, 4008-4018.

3 N. Ning, L. Hu, P. Yao, H. Wu, J. Han, L. Zhang, H. Tian and M. Tian, J. Appl. Polym. Sci., 2015, 133, DOI: 10.1002/ app.43043.

4 J. Oderkerk and G. Groeninckx, Polymer, 2002, 43, 22192228.

5 C. Antunes, A. Machado and M. Van Duin, Rubber Chem. Technol., 2009, 82, 492-505.

6 K. Lu, M. van Duin, J. Loos and G. de With, Polymer, 2012, 53, 4171-4177. 
7 A. Nicolini, T. L. Á. de Campos Rocha and M. A. Maldaner Jacobi, J. Appl. Polym. Sci., 2008, 109, 3093-3100.

8 M. D. Ellul, A. H. Tsou and W. Hu, Polymer, 2004, 45, 33513358.

9 K. Premphet and W. Paecharoenchai, J. Appl. Polym. Sci., 2002, 85, 2412-2418.

10 L. Wang, N. Ning, L. Zhang, Y. Lu, M. Tian and T. Chan, Composites, Part A, 2013, 47, 135-142.

11 M. Roy, M. van Duin, A. B. Spoelstra and J. G. Goossens, Soft Matter, 2010, 6, 1758-1768.

12 M. Tian, J. Han, H. Zou, H. Tian, H. Wu, Q. She, W. Chen and L. Zhang, J. Polym. Res., 2012, 19, 1-13.

13 J. D. Van Dyke, M. Gnatowski and A. Burczyk, J. Appl. Polym. Sci., 2008, 109, 1535-1546.

14 J.-H. Wu, C.-H. Li, H.-T. Chiu and Z.-J. Shong, J. Appl. Polym. Sci., 2008, 108, 4114-4121.

15 C. Antunes, M. Van Duin and A. Machado, Polym. Test., 2011, 30, 907-915.

16 S. Shahbikian, P. J. Carreau, M. C. Heuzey, M. D. Ellul, J. Cheng, P. Shirodkar and H. P. Nadella, Polym. Eng. Sci., 2012, 52, 309-322.

17 G. Martin, C. Barrès, P. Sonntag, N. Garois and P. Cassagnau, Eur. Polym. J., 2009, 45, 3257-3268.

18 H. Wu, M. Tian, L. Zhang, H. Tian, Y. Wu, N. Ning and T. W. Chan, ACS Sustainable Chem. Eng., 2014, 3, 26-32.

19 C. F. Antunes, A. V. Machado and M. van Duin, Eur. Polym. J., 2011, 47, 1447-1459.

20 C. F. Antunes, M. van Duin and A. V. Machado, Mater. Chem. Phys., 2012, 133, 410-418.

21 F. Goharpey, A. Katbab and H. Nazockdast, J. Appl. Polym. Sci., 2001, 81, 2531-2544.
22 F. Goharpey, A. Katbab and H. Nazockdast, Rubber Chem. Technol., 2003, 76, 239-252.

23 A. V. Machado, C. F. Antunes and M. van Duin, in Novel Trends in Rheology Iv, AIP Conference Proceedings, ed. M. Zatloukal, 2011, p. 1375, DOI: 10.1063/1.3604484.

24 B. G. Soares, M. de Oliveira, D. Meireles, A. S. Sirqueira and R. S. Mauler, J. Appl. Polym. Sci., 2008, 110, 3566-3573.

25 J. Pan, H. Hu, Z. Huang and Y. Duan, Polym.-Plast. Technol. Eng., 2001, 40, 593-604.

26 M. Tian, J. Han, H. Wu, H. Tian, Q. She, W. Chen and L. Zhang, J. Appl. Polym. Sci., 2012, 124, 1999-2006.

27 W.-c. Lee and A. T. DiBenedetto, Polymer, 1993, 34, 684-690.

28 H. Wu, M. Tian, L. Zhang, H. Tian, Y. Wu and N. Ning, Soft Matter, 2014, 10, 1816-1822.

29 P. Yao, H. Wu, N. Ning, L. Zhang, H. Tian, Y. Wu, G.-H. Hu, T. W. Chan and M. Tian, RSC Adv., 2016, 6, 11151-11160.

30 N. Vennemann, K. Bökamp and D. Bröker, Macromol. Symp., 2006, 245(1), 641-650.

31 P. Yao, H. Wu, N. Ning, L. Zhang, H. Tian, Y. Wu, G.-H. Hu, T. W. Chan and M. Tian, RSC Adv., 2016, 6, 30004-30013.

32 S. Chattopadhyay, T. Chaki and A. K. Bhowmick, J. Appl. Polym. Sci., 2001, 79, 1877-1889.

33 S. Wu, J. Appl. Polym. Sci., 1988, 35, 549-561.

34 A. R. Payne, J. Appl. Polym. Sci., 1962, 6, 368-372.

35 J. Fröhlich, W. Niedermeier and H.-D. Luginsland, Composites, Part A, 2005, 36, 449-460.

36 C. Rajesh, G. Unnikrishnan, E. Purushothaman and S. Thomas, J. Appl. Polym. Sci., 2004, 92, 1023-1030.

37 J. Oderkerk, G. de Schaetzen, B. Goderis, L. Hellemans and G. Groeninckx, Macromolecules, 2002, 35, 6623-6629.

38 M. C. Boyce, O. Yeh, S. Socrate, K. Kear and K. Shaw, J. Mech. Phys. Solids, 2001, 49, 1343-1360. 